\title{
Relationships between incivility and stress and self-efficacy among nursing students in clinical settings
}

\author{
Eunhee Hong ${ }^{1}$, HyeJin Lee ${ }^{1}$, Vivien Dee ${ }^{2}$, Younglee Kim*3 \\ ${ }^{1}$ Nursing, Seoul Women's College of Nursing, Seoul, South Korea \\ ${ }^{2}$ Nursing, Azusa Pacific University, California, USA \\ ${ }^{3}$ California State University San Bernardino, San Bernardino, USA
}

Received: September 24, 2018

DOI: $10.5430 /$ ijh.v5n1p16
Accepted: November 7, $2018 \quad$ Online Published: November 13, 2018

URL: https://doi.org/10.5430/ijh.v5n1p16

\begin{abstract}
Background: In nursing education, clinical practice is a crucial process for students to learn and practice knowledge and skills for becoming healthcare professionals.

Objective: To investigate the effects of the experience of incivility on nursing students' stress and self-efficacy in clinical settings. Methods: A descriptive cross-sectional study was conducted using self-administered surveys by a convenience sample of 195 nursing students in South Korea. The surveys included sociodemographic questions, the 13-item Korean version of Uncivil Behavior in Clinical Nursing Education (K-UBCNE), the 24-item Korean versions of Beck-Srivastava Stress Inventory (K-BSSI), and the 24-item of Academic Self-Efficacy (ASE).

Results: The average age of our sample was 22.33 years $( \pm 2.39)$. Among 195 study participants, junior students were 123 $(63.1 \%)$ and senior students were 72 (36.9\%). Mean score of total incivility by the K-UBCNE among the seniors was significantly higher than the juniors $(t=-2.985, p=.002)$. Pearson correlations results indicated that the nursing students' incivility experience was positively correlated with the K-BSSI $(r=.679, p<.01)$, and the ASE $(r=.680, p<.01)$. Lastly, Clinical Education Environment $(t=1.985, p=.049)$, Undesired Role Model $(t=6.650, p=.000)$ and Interpersonal Conflict $(t=2.486, p=.014)$ from K-BSSI were the predictors for incivility, $\mathrm{F}(7,195)=28.110, p=.000$.

Conclusions: Incivility adversely influences students' learning. Nurse educators and RNs should recognize the serious implications of incivility and develop effective interventions to combat incivility. Further studies of stress, self-efficacy, and incivility in the clinical sites are warranted.
\end{abstract}

Key Words: Clinical settings, Incivility, Stress inventory, Self-efficacy, Nursing student

\section{INTRODUCTION}

In nursing education, clinical practice is a crucial process for students to learn and practice knowledge and skills for becoming healthcare professionals in clinical areas. ${ }^{[1]}$ However, while applying their knowledge and skills to practice, nursing students often experience tension, stress, psychological tiredness, and helplessness. ${ }^{[2]}$ Nursing students, in particu- lar, experience incivility in the form of neglect, indifference, and unpleasant expressions and tones from registered nurses $(\mathrm{RN})$ in clinical learning environments. ${ }^{[3]}$ Incivility is an antisocial behavior with a vague intention causing harm to others by bullying or verbal abuse; however, it has been easily ignored.$^{[4]}$ Incivility starts with a trivial task and leads to negative relationships, leaving an enormous psychological

\footnotetext{
*Correspondence: Younglee Kim; Email: younglee.kim@ @susb.edu; Address: California State University San Bernardino, 5500 University Pkwy, San Bernardino, CA 92407, USA.
} 
scar on individuals. ${ }^{[5]}$ Incivility is critical because it can spread widely from individual behavior to an organizational system; therefore, it can be a problem for all members, not for individuals alone. ${ }^{[6]}$

According to Jones and Johnson, ${ }^{[7]}$ nursing students experienced more stress during the first year of their nursing program. In a study by Baker, ${ }^{[8]}$ students' grade point averages (GPAs) and their study time were the significant factors for nursing students' perceived stress during the nursing programs. Stress is defined as the adverse reaction people have to excessive pressure or other types of demand placed on them. ${ }^{[9]}$ It is a reaction to physical or psychological damage or imbalance due to bad or difficult situations or relationships. Stress is one of the big problems that occur in many workplaces. ${ }^{[10]}$ It affects each other in organizations and negatively affects workers' health and their work outcomes. ${ }^{[11]}$ Nursing students can also be exposed to stressful situations at clinical sites as well as other workers. Stress can also damage nursing students' critical thinking process to perform patient care and hinder them from completing their clinical practice. ${ }^{[2]}$ In particular, high levels of emotional stress from RNs' incivility behaviors can affect nursing students' educational outcomes in clinical areas. ${ }^{[4]}$

Jeon and $\mathrm{Oh}^{[4]}$ found a significant association between students' incivility experience and their self-efficacy in clinical sites. Self-efficacy is a mechanism of determining individual ability to utilize his/her owns cognitive resources, motives, or various behaviors with firm objective for confronting problems. ${ }^{[12]}$ Bandura ${ }^{[13,14]}$ notes that self-efficacy is affected by four factors: experience in success, diverse life experience, verbal persuasion, and physiological and emotional states. Of these four factors, experience in success by performance situations, task difficulty, and efforts is the most a critical factor in forming self-efficacy. ${ }^{[13,14]}$ Self-efficacy is individual intention to determine own behavior and thinking and is a spontaneous desire to make unlimited efforts for success. ${ }^{[2]}$ In order to maximize self-efficacy, it is vital to minimize outside help and increase individual efforts for success ${ }^{[13,14]}$ within positive support and environment. Self-efficiency is an indicator of nursing students' clinical performance. ${ }^{[15]}$ It is a necessary component to improve students' self-confidence and independence for patient care in various clinical situations and settings. However, there is still a lack of data to fully understand the associations between nursing students' self-perceived incivility and stress or their self-efficacy in nursing education, in particular, the clinical learning environment. Therefore, our study was conducted to investigate the effects of nursing students' incivility experience in clinical learning environments on their stress and self-efficacy.

\section{MeTHODS}

\subsection{Research questions}

- What were the differences in the experiences of incivility in the clinical areas between the junior and senior nursing students?

- What were the nursing students' experiences with incivility in clinical areas that affected their stress and self-efficacy?

\subsection{Design and participants}

For our study, a descriptive cross-sectional design was utilized using a convenience sample of 195 nursing students in the BSN program at SWCN, South Korea. All study participants were Koreans, spoke and wrote in the Korean language. All were age 18 and above and had at least six months of clinical experience in hospital areas (about 150 hours). There was no self-report by the participants of having mental illness or taking any psychiatric medication/treatment. The required sample size for our study was at least 82 , based on a power analysis for an alpha of .05 , power of .80 and a moderate effect size of .30 ( $\mathrm{G}^{*}$ Power 3.1.9.2).

\subsection{Human subject approval}

Our study received IRB approval from SWCN (No. SWCN201705-HR-005) and was carried out in accordance with the requirements of human subject research. The survey was conducted from June 10, 2017 to August 31, 2017. Our study team provided information on the study's purpose and procedures, and explained that the collected data would be kept confidential, processed anonymously and not be used for any other purposes. The participants then gave their written consents and completed self-administered surveys which took 15 minutes to complete.

\subsection{Instruments}

The survey for our study included 4 sociodemographic items: age, gender, year in nursing program, and religion, a 13item Korean version of Uncivil Behavior in Clinical Nursing Education (K-UBCNE), a 24-item Korean version of Beck-Srivastava Stress Inventory (K-BSSI), and a 24-item on Academic Self-efficacy (AS).

\subsubsection{Uncivil Behavior in Clinical Nursing Education (UBCNE)}

In 2011, Anthony and Yastik ${ }^{[16]}$ developed the UBCNE to measure nursing students' incivility experience during their clinical practice. This instrument consists of 20 questions with 5 -point Likert scale $(0=$ never to $4=$ very often $)$ to ask how often nursing students felt rude, exclusive, or dismissive feelings during their clinical practice. However, Jo and $\mathrm{Oh}^{[17]}$ modified the UBCNE for Korean participants 
through reliability and validity analysis in 2016. The Korean version of the UBCNE included a total 13 items with three subscales: Hostile/Mean (H-M; 5 items), Exclusionary behaviors (EXBEV; 5 items), and Dismissive (DIS; 3 items). The possible score of the Korean UBCNE is 0 to 52 ; higher scores indicate more experiences with incivility. Cronbach's alpha coefficient of the UBCNE was .88 in the research by Anthony and Yastik ${ }^{[16]}$ whereas it was .90 in our study.

\subsubsection{Beck-Srivastava Stress Inventory (BSSI)}

In 1991, Beck and Srivastava ${ }^{[18]}$ developed the Stress Inventory (BSSI) to measure stress in nursing students in various years of BSN programs. This instrument consists of 44 questions with 5 -point Likert scale $(1=$ never to $5=$ very often) to ask how stressful nursing students found in diverse learning experience. Similarly, in 2005, Kim and Lee ${ }^{[19]}$ modified this inventory for Korean participants. The Korean version of BSSI included a total 24 items with five subscales: Clinical Education Environment (CEE; 5 items), Undesired Role Model (URM; 6 items), Clinical Practice Workload (CPW; 4 items), Interpersonal Conflict (IC; 4 items), and Conflict with Patient (CP; 5 items). The possible scores of the K-BSSI range from 24 to 120 ; higher scores indicate more stressful experiences. Cronbach's alpha coefficient of the SI was .91 in the research by Beck and Srivastava ${ }^{[18]}$ whereas it was .89 in our study.

\subsubsection{Academic Self-Efficacy (ASE)}

In 2001, Kim and Park ${ }^{[20]}$ developed the Academic SelfEfficacy (ASE) to measure students' abilities to succeed in specific situations or accomplish tasks in academic areas. This instrument consists of 24 question items using a 5point Likert scale $(1=$ never to $5=$ very often $)$ with three subcategories: Self-Confidence (SC; 7 items), Self-Regulatory Efficacy (SRE; 12 items), and Task Difficulty Preference (TDP; 5 items). The possible scores of the ASE range from 24 to 120; higher scores indicate higher levels of self-efficacy ability. Cronbach's alpha coefficient of the ASE was .88 in the article by Kim and Park in 2001 but it was .87 in our study sample.

\subsection{Data analysis}

Data analysis was performed using the IBM Statistical Package for Social Sciences (SPSS) version 24. Descriptive statistics included frequency, percentages (\%), and mean scores (M) with standard deviations (SD) for the general characteristics of the sample population.

The sample was divided into two groups: junior nursing students group and senior nursing students group. Chi-square was used to determine the general characteristic differences between these two groups, while $t$-test was used to deter- mine the statistical differences of incivility, Stress, and Selfefficacy between the junior group and senior group. Pearson correlation coefficients tested the correlations among incivility, stress, and self-efficacy. Lastly, multiple regression analysis identified the significant predictors for incivility in our Korean sample $(\mathrm{N}=195)$.

\section{RESULTS}

\subsection{Sample characteristics}

The mean age of the sample $(\mathrm{N}=195)$ was 22.33 years (SD =2.39). Among 195 female students, the juniors were 123 $(63.1 \%)$ and the seniors were $72(36.9 \%)$. More than half of the students $(n=110,56.4 \%)$ answered that they had no religion. There were no significant differences found among the two groups; e.g., junior and senior on age, employment and religion.

\subsection{Groups differences of incivility, stress, and self- efficacy}

The differences of incivility, stress, and self-efficacy between the juniors and seniors are shown in Table 1. Results showed no mean scores differences of incivility by the K-UBCN, Stress by the K-BSSI, and Self-Efficacy by the ASE between the juniors group and seniors group. However, the mean scores of the total UBCNE (raged from 0 to 52) in the junior group and the senior group were $21.24 \pm 9.56$ and $25.79 \pm$ 10.69. The mean scores of the total K-BSSI (ranged from 24 to 120) for the junior group and the senior group were $68.24 \pm 12.43$ and $77.49 \pm 13.12$. The mean scores of the total ASE (ranged from 24 to 120) between the juniors and seniors were $78.84 \pm 7.19$ and $83.24 \pm 6.43$. According to the $t$-test, the senior students' mean score of total incivility was significantly higher than that of the junior students $(t=$ $-2.980, p=.003)$. The mean scores of the total K-BSSI and the total ASE in the senior students were also significantly higher than the junior students $(t=-4.912, p=.000 ; t=$ $-5.386, p=.000)$. See Table 1 for details.

\subsection{Intercorrelations among incivility, stress, and self- efficacy}

According to the results of Pearson correlation coefficients, there were 1 of 91 correlations and 28 of 91 correlations that were significant at $p<.05$ (2-tailed) and $p<.01$ (2-tailed); however, only $4 \%$ (four of 91 ) of the correlations were negative. The correlations ranged from -.002 to +.935 . Table 2 also showed that correlations between total incivility and total Stress $(r=.679, p<.01)$, and total incivility and total Self-Efficacy $(r=.680, p<.01)$ were statistically significant. See Table 2 for details. 


\subsection{Incivility predictors}

regression analysis in our study. Table 3 showed that this

Base on the results of Pearson correlation, CEE, URM, CPW,

IC, CP of the K-BSSI instrument and SC and SRE of the

ASE instrument were independent variables and the total

incivility score was a dependent variable to conduct multiple analysis was significant, $\mathrm{F}(7,195)=28.115, p=.001$. In the details, $\mathrm{R}^{2}$ was .513 and adjusted $\mathrm{R}^{2}$ was .495 , indicating about $50 \%$ variance of incivility was predicted by CEE, URM, and IC of K-BSSI.

Table 1. Junior and senior nursing students incivility, stress, and self-efficacy in clinical settings $(\mathrm{N}=195)$

\begin{tabular}{|c|c|c|c|c|c|c|}
\hline \multirow{2}{*}{ Instruments } & \multirow{2}{*}{$\begin{array}{l}\text { Juniors } \\
\text { M (SD) }\end{array}$} & \multirow{2}{*}{$\begin{array}{l}\text { Seniors } \\
M \text { (SD) }\end{array}$} & \multicolumn{2}{|c|}{$95 \% \mathrm{CI}$} & \multirow{2}{*}{$t$} & \multirow{2}{*}{$p$} \\
\hline & & & Lower & Upper & & \\
\hline Total Incivility (K-UBCNE) & $21.24(9.56)$ & 25.79 (10.69) & -7.566 & -1.529 & -2.980 & $.003^{* *}$ \\
\hline Hostile/Mean & $8.85(3.91)$ & $11.03(4.87)$ & -3.507 & -.840 & -2.875 & $.002^{* *}$ \\
\hline Exclusionary Behaviors & $8.390(4.51)$ & $10.31(4.93)$ & -3.318 & -.512 & -2.700 & $.003^{* *}$ \\
\hline Dismissive & $4.00(2.39)$ & $4.456(2.57)$ & -1.193 & .276 & -1.234 & .219 \\
\hline Total Stress (K-BSSI) & $68.24(12.43)$ & $77.49(13.12)$ & -13.026 & -5.475 & -4.912 & $.000^{* *}$ \\
\hline Clinical Education Environment & $16.33(3.23)$ & $18.40(3.57)$ & -3.081 & -1.058 & -4.046 & $.000^{* *}$ \\
\hline Undesired Role Model & $16.46(4.42)$ & $19.46(4.55)$ & -4.323 & -1.683 & -4.496 & $.000^{* *}$ \\
\hline Clinical Practice Workload & $12.81(2.81)$ & $14.96(2.90)$ & -2.986 & -1.304 & -5.042 & $.000^{* *}$ \\
\hline Interpersonal Conflict & $9.62(2.53)$ & $10.81(2.60)$ & -1.943 & -.432 & -3.106 & $.002^{* *}$ \\
\hline Conflict with Patient & $13.02(3.53)$ & $13.86(4.15)$ & -1.000 & .309 & -1.449 & $.150^{* *}$ \\
\hline Total Self-Efficacy (ASE) & 78.84 (7.19) & $83.24(6.43)$ & -6.367 & -2.430 & -4.412 & $.000^{* *}$ \\
\hline Self-Confidence & $23.37(3.24)$ & $24.88(3.25)$ & -2.453 & -.549 & -3.114 & $.002^{* *}$ \\
\hline Self-Regulatory Efficacy & $38.86(3.75)$ & $40.81(3.37)$ & -2.974 & -.914 & -3.728 & $.000^{* *}$ \\
\hline Task Difficulty Preference & $16.60(2.32)$ & $17.56(2.78)$ & -1.722 & -.185 & -2.456 & $.015^{*}$ \\
\hline
\end{tabular}

Note. CI: Confidence Interval, K-UBCNE: Korean version-uncivil behavior in clinical nursing education, K-BSSI: Korean versions of Beck-Srivastava Stress Inventory, ASE: Academic Self-Efficacy. ${ }^{*} p<.05$ (2-tailed), ${ }^{* *} p<.01$ (2-tailed)

Table 2. Intercorrelations among incivility, stress, and self-efficacy $(\mathrm{N}=195)$

\begin{tabular}{|c|c|c|c|c|c|c|c|c|c|c|c|c|c|c|}
\hline & T-I & H-M & EX-BEH & DIS & T-BSSI & CEE & URM & CPW & IC & CP & T-ASE & SC & SRE & TDP \\
\hline T-I & 1 & & & & & & & & & & & & & \\
\hline $\mathrm{H}-\mathrm{M}$ & $.916^{* *}$ & 1 & & & & & & & & & & & & \\
\hline EX-BEH & $.906^{* * *}$ & $.720^{* *}$ & 1 & & & & & & & & & & & \\
\hline DIS & $.759^{* * *}$ & $.621^{* *}$ & $.536^{* * *}$ & 1 & & & & & & & & & & \\
\hline T-BSSI & $.679^{* * *}$ & $.623^{* *}$ & $.604^{* * *}$ & $.537^{* * *}$ & 1 & & & & & & & & & \\
\hline CEE & $.481^{* * *}$ & $.466^{* *}$ & $.433^{* * *}$ & $.325^{* *}$ & $.740^{* * *}$ & 1 & & & & & & & & \\
\hline URM & $.668^{* * *}$ & $.625^{* *}$ & $.613^{* * *}$ & $.468^{* * *}$ & $.854^{* *}$ & $.530^{* *}$ & 1 & & & & & & & \\
\hline CPW & $.453^{* * *}$ & $.405^{* *}$ & $.418^{* * *}$ & $.346^{* *}$ & $.785^{* *}$ & $.579^{* *}$ & $.633^{* *}$ & 1 & & & & & & \\
\hline IC & $.499^{* * *}$ & $.431^{* * *}$ & $.450^{* * *}$ & $.428^{* * *}$ & $.699^{* * *}$ & $.389^{* * *}$ & $.503^{* * *}$ & $.420^{* * *}$ & 1 & & & & & \\
\hline СР & $.433^{* * *}$ & $.385^{* *}$ & $.339^{* * *}$ & $.453^{* * *}$ & $.697^{* * *}$ & $.313^{* *}$ & $.449^{* *}$ & $.378^{* *}$ & $.474^{* *}$ & 1 & & & & \\
\hline T-ASE & $.362^{* * *}$ & $.632^{* *}$ & $.603^{* * *}$ & $.526^{* * *}$ & $.976^{* * *}$ & $.747^{* *}$ & $.831^{* *}$ & $.778^{* * *}$ & $.676^{* *}$ & $.657^{* * *}$ & 1 & & & \\
\hline SC & $.362^{* * *}$ & $.351^{* *}$ & $.342^{* *}$ & $.212^{* * *}$ & $.479^{* * *}$ & $.451^{* *}$ & $.394^{* * *}$ & $.351^{* * *}$ & $.294^{* *}$ & $.311^{* *}$ & $.807^{* * *}$ & 1 & & \\
\hline SRE & $.318^{* * *}$ & $.316^{* *}$ & $.268^{* * *}$ & $.235^{*}$ & $.370^{* * *}$ & $.392^{* *}$ & $.299^{* *}$ & $.359^{* *}$ & $.237^{* *}$ & .131 & $.897^{7 *}$ & $.659^{* *}$ & 1 & \\
\hline TDP & .059 & .092 & .028 & -.026 & -.007 & -.002 & .005 & .059 & .002 & -.077 & $.475^{* * *}$ & .021 & $.223^{* * *}$ & 1 \\
\hline
\end{tabular}

Note. T-I: Total-Incivility, H-M: Hostile/Mean, EX-BEH: Exclusionary Behaviors, DIS: Dismissive, T-BSSI: Total Beck-Srivastava Stress Inventory, CEE: Clinical Education Environment, URM: Undesired Role Model, CPW: Clinical Practice Workload, IC: Interpersonal Conflict, CP: Conflict with Patients, T-AES: Total-Academic Self-Efficacy, SC: Self-Confidence, SRE: Self-Regulatory Efficacy, TDP: Task Difficulty Preference. ${ }^{*} p<.05$ (2-tailed), ${ }^{* *} p<.01$ (2-tailed) 
Table 3. Predictors of incivility experience among nursing students in clinical settings ( $\mathrm{N}=195)$

\begin{tabular}{|c|c|c|c|c|c|c|}
\hline \multirow{2}{*}{ Variables } & \multicolumn{2}{|c|}{$95 \%$ CI } & \multirow{2}{*}{ Unstandardized B } & \multirow{2}{*}{$\begin{array}{l}\text { Standardized } \\
\text { Coefficients } \beta\end{array}$} & \multirow{2}{*}{$t$} & \multirow{2}{*}{$p$} \\
\hline & Lower & Upper & & & & \\
\hline Constant & -30.706 & -8.271 & -19.489 & - & -3.427 & $.001^{* *}$ \\
\hline BSS1-Clinical Education Environment & .002 & .786 & .394 & .135 & 1.985 & $.049^{*}$ \\
\hline BSSI-Undesired Role Model & .748 & 1.378 & 1.063 & .488 & 6.650 & $.000^{* *}$ \\
\hline BSSI-Clinical Practice Workload & -.745 & .222 & -.261 & -.077 & -1.066 & .288 \\
\hline BSSI-Interpersonal Conflict & .127 & 1.101 & .614 & .157 & 2.486 & $.014^{*}$ \\
\hline BSSI-Conflict with Patient & -.012 & .648 & .318 & .118 & 1.901 & .059 \\
\hline ASE-Self-Confidence & -.489 & .394 & -.052 & -.017 & -.230 & .818 \\
\hline ASE-Self-Regulatory Efficacy & -.093 & .668 & .288 & .105 & 1.492 & .137 \\
\hline \multicolumn{7}{|l|}{$\mathrm{R}^{2}=.513$} \\
\hline \multicolumn{7}{|l|}{ Adjusted $\mathrm{R}^{2}=.494$} \\
\hline$F(7,195)$ & & & & & 28.110 & $.000^{* *}$ \\
\hline
\end{tabular}

Note. CI: Confidence Interval, BSSI: Beck-Srivastava Stress Inventory, ASE: Academic Self-Efficacy, ${ }^{*} p<.05,{ }^{* *} p<.01$

\section{Discussion}

In our sample, the total incivility score by the K-UBCNE was $21.24(\mathrm{SD}=9.56)$ in the junior group and $25.79(\mathrm{SD}=$ 10.69) in the senior group. However, in Hong, et al. ${ }^{[6]}$ study of Korean senior nursing students, the total incivility score by using the same instrument, K-UBCNE, was $10.54 \pm 7.35$ Interestingly, our study found that among the three subcategories of the K-UBCNE, the scores of H-M and EXBEV in the senior student group were significantly higher than the junior student group. We did not identify the significant factors for incivility experience among the seniors in our study, but we noticed that they had their clinical practice in critical units such as Intensive Care Unit (ICU) to care for patients with severe and life-threatening illnesses or injuries.

Generally, ICU requires constant and close monitoring of patients' health conditions. Because of the nature of work in critical care units, ICU healthcare professionals are needed with advanced knowledge and skills for patient care; thus, ICU working environment is more tense and stressful than other general care units in hospital settings. ${ }^{[21,22]}$ Therefore, the senior students in our sample may have experienced more stressful situations than the junior students during their clinical practice which may have added to an increase in incivility rates. Cottrell ${ }^{[23]}$ stated that taking care of critically ill patients is a huge challenge and nurses should be well prepared with a thorough orientation to handle diverse complexed and urgent situations as a way to decrease incivility in critical acre units. In clinical settings, professionals and skilled nurses are regarded as good and respected healthcare providers. ${ }^{[24]}$ Consequently, many hospitals provide intensive internship programs to prepare nurses for a career in critical care. Likewise, senior nursing students may need in-depth orientation and more skills to practice with clinical instructors on the care of critically ill patients before they are placed on critical care units.

The senior nursing students' stress score by the BSSI was also significantly higher than the junior group $(t=-4.912$, $p=.000)$. Based on our study findings, we can expect that nursing students' incivility experience will vary from unit to unit and in particular, with more incivility situations occurring in critical units among nursing students than in other units. In order to provide evidence to support this assumption; further studies to compare incivility among nursing students in various clinical units are essential.

Interestingly, the senior students in our sample significantly had higher score of self-efficacy by the AS instrument than the junior students $(t=-5.386, p=.000)$. Senior nursing students are almost ready to work as RNs in clinical areas. Their self-esteem as an RN is important. Self-efficacy can increase independence and confidence. ${ }^{[25]}$ Self-efficacy also raises job satisfaction in the nursing profession ${ }^{[26]}$ and RNs retention rate in working sites. ${ }^{[27]}$ Self-efficacy is also important to junior nursing students for success of their clinical practice education. Masoudi and colleagues ${ }^{[27]}$ suggested that clinical instructors should recognize the seriousness of incivility in clinical areas and provide nursing students with opportunities to independently practice patient care with higher levels of self-confidence under supportive supervision to improve their self-efficacy.

In our study we also found that the nursing students' stress and self-efficacy were significantly associated with incivil- 
ity experience. In order to decrease incivility experience in clinical areas, it is essential for clinical instructors to create an intervention such as clinical counseling for nursing students to deal with bad and stressful situations and feelings during their clinical practice. It is anticipated that our study findings will provide nursing educators with a better knowledge of clinical incivility among nursing students and furthermore, assist clinical instructors or nursing educators to design proper intervention to counter incivility in clinical learning environments.

Our study sample included junior and senior nursing students primarily in the critical care areas in the hospital setting; therefore, results are limited in its generalizability. Comparative studies in various clinical care settings as learning environment for nursing students are urgently needed. Qualitative studies to gather nursing students' in-depth personal experience under a systematic subjective approach should be considered. Also, more studies to identify risk factors for incivility among nursing students are also required to create effective intervention for the prevention of incivility.

\section{Conclusions}

Nursing students experience incivility in clinical settings. Incivility experience can significantly increase the perception of job stress and decrease self-efficacy with patients' care in the hospitals. ${ }^{[28]}$ Consequently, nurse educators should be aware of the meaning and impact of incivility for nursing students. Nurse educators should search for better solutions to improve the clinical experience of nursing students and increase their self-efficacy through de-briefing or support groups offered during their clinical experience.

\section{CONFLICTS OF INTEREST Disclosure}

The authors declared no conflict of interest.

\section{REFERENCES}

[1] Park JW, Ha NS. Nursing students' clinical experiences. Journal of Korean Academy of Psychiatric and Mental Health Nursing. 2003; 12(1): 27-35.

[2] Whang SJ. The Relationship between clinical stress, self-efficacy, and self-esteem of nursing college students. Journal of Korean Academic Society of Nursing Education. 2006; 12(2): 205-213. Available from: http://uci.or.kr/G704-001961.2006.12.2.004

[3] Birks MM, Cant RP, Budden LM, et al. Uncovering degrees of workplace bullying: A comparison of baccalaureate nursing students' experiences during clinical placement in Australia and the UK. Nurse Education In Practice. 2017; 2514-21. https://doi.org/10.101 $6 / j . n e p r .2017 .04 .011$

[4] Jeon MK, Oh JW. Relationship between rudeness, burnout, major satisfaction and self-efficacy which nursing students experience during clinical practice. Journal of Digital Convergence. 2017; 15(1): 339-346. https://doi.org/10.14400/JDC.2017.15.1.339

[5] Kim SY, Kim JK, Park KO. Path analysis for workplace incivility, empowerment, burnout, and organizational commitment of hospital nurses. Journal of Korean Academy of Nursing Administration. 2013; 19(5): 555-564. https://doi.org/10.11111/jkana. 201 3.19.5.555

[6] Hong YK, Kim YJ, Son HM. Effect of nurses' incivility experienced by nursing student, coping on burnout in clinical practice. Journal of Korean Academy of Nursing Administration. 2016; 22(4): 323-331. https://doi.org/10.11111/jkana.2016.22.4.323

[7] Jones MC, Johnston DW. Distress, stress and coping in firstyear student nurses. Journal of Advanced Nursing. 1997; 26(3): 475-482. https://doi.org/10.1046/j.1365-2648.1997.t01 -5-00999. $\mathrm{x}$

[8] Baker M. Nursing student stress and demographic factors. Presented to the faculty of the school of nursing California State University, San Marcos. 2012 (degree of master). Available from: http://cs usmdspace. calstate. edu/handle/10211.3/10211.8_146

[9] Health Safety Executive. Managing the causes of workrelated stress: A step-by-step approach using the manage- ment standards. 2017 May 5; 7p. Available from: https: //safetyresourcesblog.files . wordpress.com/2014/10/ managing-the-causes-of-work-related-stress-a-ste p-by-step-approach-using-management-standards.pdf

[10] Skakon J, Nielsen K, Borg V, et al. Are leaders' well-being, behaviors and style associated with the affective well-being of their employees? A systematic review of three decades of research. Work \& Stress. 2010; 24(2): 107-139. https://doi.org/10.1080/02678373.2 010.495262

[11] Leiter MP, Bakker AB, Maslach C. Burnout at work: A psychological perspective. New York, NY: Psychology Press; 2014. https://doi.org/10.4324/978131589416

[12] Kim AL. The effect of compassion fatigue, ego resilience, clinical practice self-efficacy on stress on clinical practice of the nursing students. Korean Association for Learner-centered Curriculum and Instruction (KALCI). 2017; 17(21): 646-663. https ://doi.org/ 10.22251/jlcci.2017.17.21.645

[13] Bandura A. Self-efficacy: toward a unifying theory of behavioral change. Psychological Review. 1977; 84(2): 191-215. PMid:847061. https://doi.org/10.1037/0033-295X.84.2.191

[14] Bandura A. Social cognitive theory: An agentic perspective. Annual Review of Psychology. 2001; 52(1): 1-26. PMid:11148297. https://doi.org/10.1146/annurev.psych.52.1.1

[15] Zengin N, Pinar R, Akinci AC. et al. Psychometric properties of the self-efficacy for clinical evaluation scale in Turkish nursing students. Journal of Clinical Nursing. 2014; 23(7-8): 976-984. PMid:23876212. https://doi.org/10.1111/jocn. 12257

[16] Anthony M, Yastik J. Nursing Students' experiences with incivility in clinical education. Journal of Nursing Education. 2011; 50(3): 140-144. PMid:21323254. https://doi.org/10.3928/014848 34-20110131-04

[17] Jo SO, Oh J. Validity and reliability of the Korean version of a tool to measure uncivil behavior in clinical nursing education. Journal of Korean Academic Society of Nursing Education. 2016; 22(4): 537-548. https://doi.org/10.5977/jkasne.2016.22.4.537 
[18] Beck DL, Srivastava RH. Perceived level and sources of stress in baccalaureate nursing students. Journal of Nursing Education. 1991; 30(3): 127-133. PMid:1850792.

[19] Kim SL, Lee JE. Relationship among stress coping strategies, and self -esteem in nursing students taking clinical experience. The Journal of Korean Academic Society of Nursing Education. 2005; 11(1): 98-106.

[20] Kim AY, Park IY. Development and validation of academic selfefficacy scale. Korean Journal of Educational Research. 2001; 39(1): 95-123. Available from: http://www.riss.kr/link?id=A770 19759

[21] Mealer M, Shelton A, Berg B, et al. Increased prevalence of posttraumatic stress disorder symptoms in critical care nurses. American Journal of Respiratory \& Critical Care Medicine. 2007; 175(7): 693 697. PMid:17185650. https ://doi.org/10.1164/rccm. 20060 6-7350C

[22] Vahedian-Azimi A, Hajiesmaeili M, Kangasniemi M, et al. Effects of stress on critical care nurses: A national cross-sectional study. Journal of Intensive Care Medicine. 2017. https ://doi .org/10 $.1177 / 0885066617696853$
[23] Cottrell D, Kendall SM. Are you ready to move into critical care? American Journal of Nursing. 2010; 110(1): 20-21. PMid:20032683. https ://doi.org/10.1097/01.NAJ .0000366156.41070.33

[24] Brady M. Hospitalized children's views of the good nurse. Nursing Ethic. 2009; 16(5): 543-560. PMid:19671642. https://doi.org/ 10.1177/0969733009106648

[25] Bandura A. Perceived self-efficacy in cognitive development and functioning. Educational Psychologist. 1993; 28(2): 117-48. https : //doi.org/10.1207/s15326985ep2802_3

[26] Duggleby W, Cooper D, Penz K. Hope, self-efficacy, spiritual wellbeing and job satisfaction. Journal of Advanced Nursing. 2009; 65(11): 2376-85. PMid:19737323. https ://doi.org/10.1111/ j.1365-2648.2009.05094.x

[27] Masoudi Alavi N. Self-efficacy in nursing students. Nursing and Midwifery Studies. 2014; 3(4): e25881. PMid:25741520. https: //doi.org/10.17795/nms journal25881

[28] Kim SY, Yoon SH. Effect of incivility experienced by clinical nurses on job stress and the moderating effect of self-efficacy. Journal of Korean Academic Nurse Administration. 2017; 23(1): 8-17. https://doi .org/10.11111/jkana.2017.23.1.8 